\title{
On the Impact of Wind Farms on a Convective Atmospheric Boundary Layer
}

\author{
Hao Lu${ }^{1}$ - Fernando Porté-Agel ${ }^{2}$
}

Received: 20 August 2014 / Accepted: 30 May 2015 / Published online: 23 June 2015

C Springer Science+Business Media Dordrecht 2015

\begin{abstract}
With the rapid growth in the number of wind turbines installed worldwide, a demand exists for a clear understanding of how wind farms modify land-atmosphere exchanges. Here, we conduct three-dimensional large-eddy simulations to investigate the impact of wind farms on a convective atmospheric boundary layer. Surface temperature and heat flux are determined using a surface thermal energy balance approach, coupled with the solution of a three-dimensional heat equation in the soil. We study several cases of aligned and staggered wind farms with different streamwise and spanwise spacings. The farms consist of Siemens SWT-2.3-93 wind turbines. Results reveal that, in the presence of wind turbines, the stability of the atmospheric boundary layer is modified, the boundary-layer height is increased, and the magnitude of the surface heat flux is slightly reduced. Results also show an increase in land-surface temperature, a slight reduction in the vertically-integrated temperature, and a heterogeneous spatial distribution of the surface heat flux.
\end{abstract}

Keywords Convective atmospheric boundary layer · Large-eddy simulation · Wind farm

\section{Introduction}

The wind field in the lowest part of the atmosphere is the most important atmospheric factor for wind-energy applications. A number of recent studies (e.g., Baidya Roy et al. 2004; Calaf et al. 2011; Porté-Agel et al. 2011; Lu and Porté-Agel 2011; Fitch et al. 2012, 2013; Abkar and Porté-Agel 2013) have examined the interaction between atmospheric boundary-layer (ABL) flow and wind farms, and have generally shown that wind-turbine blade motions reduce wind speed, enhance turbulence, and change the stability of the ABL flow. Warming

$凶$ Fernando Porté-Agel

fernando.porte-agel@epfl.ch

1 School of Energy and Power Engineering, Huazhong University of Science and Technology, Hubei, China

2 Wind Engineering and Renewable Energy Laboratory (WIRE), École Polytechnique Fédérale de Lausanne (EPFL), 1015 Lausanne, Switzerland 
effects, particularly at nighttime, have been reported in a large-eddy simulation (LES) study of a wind farm in a stably-stratified ABL (Lu and Porté-Agel 2011). Using satellite data, Zhou et al. (2012) have found a significant warming trend of up to $0.7^{\circ} \mathrm{C}$ at the land surface. Some mesoscale simulations (e.g., Baidya Roy et al. 2004; Baidya Roy 2011) have indicated cooling by wind farms during daytime; however, a high-resolution study of wind-farm impacts on the atmospheric convective boundary layer (CBL) has not been conducted to date. Considering the fast worldwide expansion of wind energy, understanding the interactions between wind farms and the $\mathrm{ABL}$ is important for predicting their performance, quantifying their impacts on local meteorology, improving their parametrization in numerical weather prediction models, and assessing their effects on collocated agricultural crops (e.g., due to local changes in temperature, evaporation and transpiration).

Computational fluid dynamics simulations can be used to study complex engineering and environmental turbulent flows, where controlled measurements are difficult or impossible to perform, especially for very large systems such as wind farms. Although several mesoscale simulations (Baidya Roy et al. 2004; Baidya Roy 2011; Fitch et al. 2012, 2013) have been performed to estimate large-scale impacts of wind farms, they do not provide insight into the flow details near the land surface, where effects on turbulent fluxes are important. Also, most simulations (e.g., Baidya Roy et al. 2004; Calaf et al. 2011; Baidya Roy 2011; Fitch et al. 2012, 2013) do not consider the wind-turbine-induced rotation forces, and assume uniform force distribution over the rotor plane. Wake rotation plays an important role in wind-turbine mixing (Lu and Porté-Agel 2011; Porté-Agel et al. 2011; Markfort et al. 2012; Zhang et al. 2013a). Failure to take into account wake-rotation effects has been shown (PortéAgel et al. 2011; Zhang et al. 2013a) to result in errors in the prediction of momentum and heat fluxes near the land surface. Parametrization of wind turbines using the actuator line model (ALM) and actuator disk with rotation model is capable of reproducing important turbulent wake features, such as the formation of helicoidal tip vortices (with the ALM), the enhanced turbulence levels at the top edge of the wakes, and the rotation of the wakes (Lu and Porté-Agel 2011; Porté-Agel et al. 2011; Wu and Porté-Agel 2011). Specifically, Lu and Porté-Agel (2011) used LES with the ALM to investigate the effects of a large wind farm on a stably-stratified ABL.

In this study, we investigate, for the first time, a dry CBL flow through extensive wind farms, with emphasis on the characteristics of wind-turbine wakes and their aggregated effect on land-atmosphere exchange (momentum and heat fluxes). The LES framework and the simulation details are described in Sect. 2, and results are presented and discussed in Sects. 3 to 5. A summary and conclusions are provided in Sect. 6 .

\section{Large-Eddy Simulation Framework}

\subsection{LES Governing Equations and Models}

We use a modified LES code that has been used in previous wind-energy studies (Porté-Agel et al. 2011; Wu and Porté-Agel 2011; Lu and Porté-Agel 2014). We aim to study the dynamics of a dry CBL that excludes moisture, and solve the filtered continuity equation, the filtered momentum conservation equations based on the Boussinesq approximation, and the filtered transport equation for potential temperature,

$$
\frac{\partial \widetilde{u}_{i}}{\partial x_{i}}=0
$$



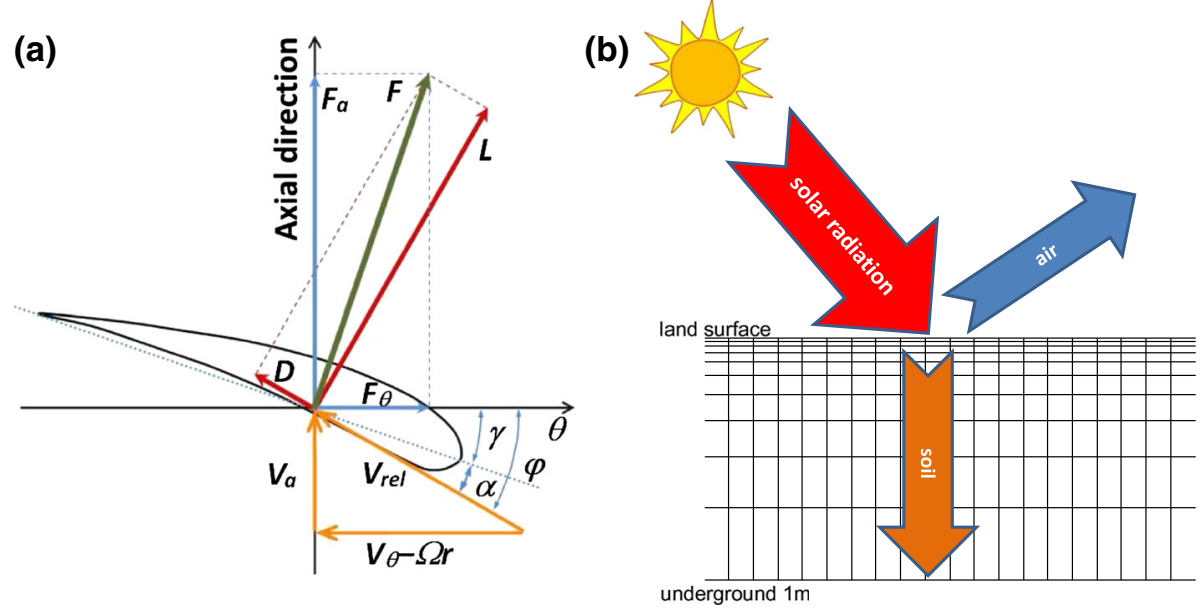

Fig. 1 a Cross-section of airfoil element showing velocities and force vectors; $\mathbf{b}$ schematic of energy balance, and structured grid with logarithmic vertical spacing used to solve the heat equation in the soil up to a depth of $1 \mathrm{~m}$

$$
\begin{gathered}
\frac{\partial \widetilde{u}_{i}}{\partial t}+\widetilde{u}_{j} \frac{\partial \widetilde{u}_{i}}{\partial x_{j}}=-\frac{\partial \widetilde{p}}{\partial x_{i}}-\frac{\partial \tau_{i j}}{\partial x_{j}}+\frac{\tilde{\theta}-\langle\widetilde{\theta}\rangle_{h}}{\Theta_{0}} \delta_{i 3} g+f_{\mathrm{c}} \varepsilon_{i j 3}\left(\widetilde{u}_{j}-U_{G, j}\right)+\mathcal{F}_{i}, \\
\frac{\partial \tilde{\theta}}{\partial t}+\widetilde{u}_{j} \frac{\partial \tilde{\theta}}{\partial x_{j}}=-\frac{\partial q_{j}}{\partial x_{j}},
\end{gathered}
$$

where the tilde $\sim$ ) represents a spatial filtering at the resolved scale $\widetilde{\Delta},\left(\widetilde{u}_{1}, \widetilde{u}_{2}, \widetilde{u}_{3}\right)=$ $(\widetilde{u}, \widetilde{v}, \widetilde{w})$ are the components of the velocity field, $\widetilde{\theta}$ is the resolved potential temperature, $\tau_{i j}=\widetilde{u_{i} u_{j}}-\widetilde{u}_{i} \widetilde{u}_{j}$ is the subgrid-scale (SGS) stress tensor, $q_{i}=\widetilde{u_{i} \theta}-\widetilde{u}_{i} \tilde{\theta}$ is the SGS flux vector, $\Theta_{0}$ is the reference temperature, $\langle\cdot\rangle_{h}$ represents a horizontal average, $g$ is the acceleration due to gravity, $f_{\mathrm{c}}$ is the Coriolis parameter, $U_{G, i}$ is the geostrophic wind speed, $\delta_{i j}$ is the Kronecker delta, $\varepsilon_{i j k}$ is the alternating unit tensor, $\widetilde{p}$ is the effective pressure, and $\mathcal{F}_{i}$ is a forcing term (e.g., wind-turbine induced forces). Since only dry air conditions are simulated (water vapour and cloud formation are not included), radiative heating and cooling in the air can be neglected (Arya 2001; Holton 2004).

We adopt the dynamic version of the recently-developed modulated gradient models (Lu and Porté-Agel 2010, 2013, 2014) for the SGS stress and for the SGS flux vector. The turbineinduced forces are parametrized using the rotating actuator disk model, which accounts for the effect of the turbine-induced flow rotation as well as the non-uniform force distribution (Wu and Porté-Agel 2011). Figure 1 shows a cross-section airfoil element in the $(\theta, x)$ plane, where $x$ is the axial direction. Denoting the tangential and axial velocity in the inertial frame of reference as $V_{\theta}$ and $V_{x}$, respectively, the local velocity relative to the rotating blade is given as $\mathbf{V}_{\text {rel }}=\left(V_{\theta}-\Omega r, V_{x}\right)$. The angle of attack is defined as $\alpha=\varphi-\gamma$, where $\varphi=\tan ^{-1}\left(V_{x} /\left(\Omega r-V_{\theta}\right)\right)$ is the angle between $V_{\text {rel }}$ and the rotor plane, and $\gamma$ is the local pitch angle. The resulting force is given by

$$
\mathbf{f}_{2 D}=\frac{\mathbf{d F}}{\mathrm{d} A}=\frac{1}{2} \rho V_{\mathrm{rel}}^{2} \frac{B c}{2 \pi r}\left(C_{\mathrm{L}} \mathbf{e}_{\mathrm{L}}+C_{\mathrm{D}} \mathbf{e}_{\mathrm{D}}\right),
$$

where an annular area of differential size is $\mathrm{d} A=2 \pi r \mathrm{~d} r, r$ is the radius, $V_{\text {rel }}$ is the local velocity relative to the rotating blade, $B$ is the number of blades, $C_{\mathrm{L}}=C_{\mathrm{L}}(\alpha, R e)$ and 
$C_{\mathrm{D}}=C_{\mathrm{D}}(\alpha, R e)$ are the lift coefficient and the drag coefficient, respectively, $c$ is the chord length, and $\mathbf{e}_{\mathrm{L}}$ and $\mathbf{e}_{\mathrm{D}}$ denote the unit vectors in the directions of the lift and the drag, respectively.

At the surface, the instantaneous wall stress is related to the velocity at the first vertical node through the application of the Monin-Obukhov similarity theory (Businger et al. 1971; Stull 1988; Arya 2001). Although this typically applies to mean quantities, it is common practice (Lu and Porté-Agel 2010) in LES of atmospheric flows to use it for instantaneous fields as follows,

$$
\left.\tau_{i 3}\right|_{w}=-u_{*}^{2} \frac{\tilde{u}_{i}}{u_{r}}=-\left(\frac{u_{r} \kappa}{\ln \left(z / z_{0}\right)-\Psi_{M}}\right)^{2} \frac{\tilde{u}_{i}}{u_{r}}(i=1,2),
$$

where $\left.\tau_{i 3}\right|_{w}$ is the instantaneous local wall stress, $u_{*}$ is the friction velocity, $z_{0}$ is the aerodynamic roughness length, $\kappa$ is the von Kármán constant, $\Psi_{\mathrm{M}}$ is the stability correction for momentum, and $u_{r}$ is the local filtered horizontal velocity at the first vertical level. In a similar manner, the surface heat flux is computed as

$$
\left.q_{3}\right|_{w}=u_{*} \theta_{*}=\frac{u_{*} \kappa\left(\theta_{\mathrm{s}}-\tilde{\theta}\right)}{\ln \left(z / z_{0, \theta}\right)-\Psi_{\mathrm{H}}},
$$

where $z_{0, \theta}$ is the thermal roughness length, $\theta_{*}$ is a temperature scale, and $\theta_{\mathrm{S}}$ is the surface (ground-level) potential temperature. Following Stull (1988) and Arya (2001), we adopt $\Psi_{\mathrm{M}}=2 \ln \left(\frac{1+x}{2}\right)+\ln \left(\frac{1+x^{2}}{2}\right)-2 \tan ^{-1}(x)+\frac{\pi}{2}$, and $\Psi_{\mathrm{H}}=2 \ln \left(\frac{1+x^{2}}{2}\right)$, where $x=$ $\left(1-\frac{15 z}{L}\right)^{1 / 4}, L=-\frac{u_{*}^{3} \widetilde{\theta}}{\left.\kappa g q_{3}\right|_{w}}$ is the Obukhov length. As adopted in previous studies (e.g., Kosovic and Curry 2000; Beare et al. 2006), the boundary-layer height, $z_{i}$, is computed as $(1 / 0.95)$ times the height at which the horizontally-averaged stress falls to $5 \%$ of its surface value. As in previous studies (e.g., Beare et al. 2006), a Rayleigh damping layer is set above $1200 \mathrm{~m}$ to limit gravity-wave reflection from the top of the domain.

To determine land-surface temperature and surface heat flux, we adopt a surface thermal energy balance approach along with 10 levels of soil temperature to a depth of $1 \mathrm{~m}$ using a logarithmic spacing, as shown in Fig. 1b. The surface thermal energy balance can be written as

$$
R_{\mathrm{N}}=\left.\frac{c_{\mathrm{s}} \alpha}{c_{\mathrm{a}}} \frac{\partial \widetilde{\theta}}{\partial z}\right|_{w}+\left.q_{3}\right|_{w},
$$

where $R_{\mathrm{N}}$ is the net solar radiation, $c_{\mathrm{s}}$ and $c_{\mathrm{a}}$ are the heat capacities of the soil and the air, and $\alpha$ is the diffusivity coefficient of the soil. A similar method was used by Deardorff (1974), who assumed horizontal homogeneity and solved the one-dimensional heat equation in the soil. In this study we relax the assumption of horizontal homogeneity, and solve a three-dimensional heat equation in the soil

$$
\frac{\partial \widetilde{\theta}}{\partial t}=\alpha \nabla^{2} \widetilde{\theta}
$$

which allows us to study the heterogeneity of the land-surface temperature and the surface heat flux.

\subsection{Numerical Set-Up}

In order to understand the impact of a wind farm on a CBL flow, we first simulate a baseline CBL case (without wind turbines). We have revised the numerical procedures adopted for 
other ABL flow cases (Moeng 1984; Mason 1989; Moeng and Sullivan 1994; Agee and Gluhovsky 1999; Sorbjan 2006; Beare et al. 2006; Conzemius and Fedorovich 2006, 2008) to make the simulated CBL suitable for studying its interactions with wind farms. In summary, the boundary layer is driven by an imposed uniform geostrophic wind speed of $15 \mathrm{~m} \mathrm{~s}^{-1}$, the Coriolis parameter is set to $f_{\mathrm{c}}=1.00 \times 10^{-4} \mathrm{rad} \mathrm{s}^{-1}$, corresponding to a latitude of about $45^{\circ}, z_{0}=0.1 \mathrm{~m}$ and $z_{0, \theta}=0.01 \mathrm{~m}, g=9.81 \mathrm{~m} \mathrm{~s}^{-2}, \theta_{0}=300 \mathrm{~K}$. The initial potential temperature profile consists of a mixed layer (with potential temperature $302 \mathrm{~K}$, which is also the initial soil temperature) up to $100 \mathrm{~m}$ with an overlying inversion of strength $0.0114 \mathrm{~K} \mathrm{~m}^{-1}$. We assume the net solar radiative flux has a constant value of $0.08 \mathrm{~K} \mathrm{~m} \mathrm{~s}^{-1}$ during the simulation. The soil is dry, its diffusivity is $5.0 \times 10^{-7} \mathrm{~m}^{2} \mathrm{~s}^{-1}$ (Deardorff 1974; Stull 1988), and its heat capacity is $1.3 \times 10^{6} \mathrm{~J} \mathrm{~m}^{-3} \mathrm{~K}^{-1}$ (Stull 1988). It should be noted that the boundary-layer height of the baseline CBL case is continuously increasing. According to previous time-scale arguments (Agee and Gluhovsky 1999), the baseline CBL case is fully developed after $3 \mathrm{~h}$ (approximately 18 large-eddy turnover times). Therefore, in order to examine the wind-turbine effects relative to the baseline case, we introduce the wind turbines only after $3 \mathrm{~h}$, and the mean velocity direction is aligned to be axial at the hub-height level. Note that during the wind-farm simulation, the wind-direction change in the wind-turbine region is not significant.

The domain is uniformly divided into $N_{x}, N_{y}$ and $N_{z}$ grid points in the $x, y$ and $z$ directions. Periodic boundary conditions are applied horizontally so that an idealized very large (effectively infinite) wind farm can be simulated. A pseudo-spectral method is adopted in the horizontal directions, and vertical derivatives are approximated with second-order central differences. The vertical domain has a height of $L_{z}=1476 \mathrm{~m}$, and the vertical grid number is $N_{z}=128$. The grid planes are staggered in the vertical with the first vertical velocity plane at a distance $\Delta z=L_{z} /\left(N_{z}-1\right)$ from the surface. Aliasing errors are corrected in the nonlinear terms using the $3 / 2$ rule (Canuto et al. 1988). The time advancement is carried out using a second-order accurate Adams-Bashforth scheme (Canuto et al. 1988). We set a constant timestep corresponding to a rather restrictive Courant-Friedrichs-Lewy number of $\approx 0.02$ to reduce the error from the time stepping.

Siemens SWT-2.3-93 wind turbines, with a rotor diameter $(D)$ of $93 \mathrm{~m}$ and a hub height of $80 \mathrm{~m}$, are 'immersed' in the flow. Details of the wind turbine can be found in Leloudas (2006), and Laursen et al. (2007). According to previous domain-size arguments (Roode and Duynkerke 2004), a horizontal domain size of $1 \sim 2$ times of the boundary-layer height is sufficient for a dry CBL simulation. In this study, the horizontal domain is approximately four times of the boundary-layer height. We vary the horizontal dimensions $\left(L_{x}\right.$ and $\left.L_{y}\right)$, the resolutions $\left(N_{x}\right.$ and $\left.N_{y}\right)$, the number of wind turbines $\left(N_{t, x}\right.$ by $\left.N_{t, y}\right)$, the layout (aligned or staggered), and the distance between wind turbines $\left(S_{x} D\right.$ by $\left.S_{y} D\right)$. The suite of LES cases is described in Table 1. For simplicity, the aligned $S_{x} \times S_{y}=X \times Y$ wind farm case is abbreviated to 'aX $\times$ Y', and the staggered $S_{x} \times S_{y}=X \times Y$ wind farm case is abbreviated to 'sX $\times$ Y.' As an example, Figs. 2 and 3 show instantaneous fields and wind-turbine induced vortices in two wind-farm cases.

\section{Mean Vertical Profiles}

Figure 4 shows vertical profiles of the mean wind speed (defined as $\left(\langle\widetilde{u}\rangle^{2}+\langle\widetilde{v}\rangle^{2}\right)^{\frac{1}{2}}$, where the angle brackets, $\langle\cdot\rangle$, represent averaging over $1 \mathrm{~h}$ and horizontal directions) and the mean potential temperature obtained from the a $5 \times 5$ wind-farm case and the baseline (no-farm) 
Table 1 Parameters of the wind-farm cases

\begin{tabular}{llll}
\hline$S_{x} \times S_{y}$ & $N_{t, x} \times N_{t, y}$ & $L_{x} \times L_{y}\left(\mathrm{~m}^{2}\right)$ & $N_{x} \times N_{y}$ \\
\hline $7 \times 7$ & $6 \times 5$ & $3906 \times 3255$ & $168 \times 280$ \\
$6 \times 6$ & $7 \times 6$ & $3906 \times 3348$ & $168 \times 288$ \\
$5 \times 5$ & $8 \times 7$ & $3720 \times 3255$ & $160 \times 280$ \\
\hline
\end{tabular}

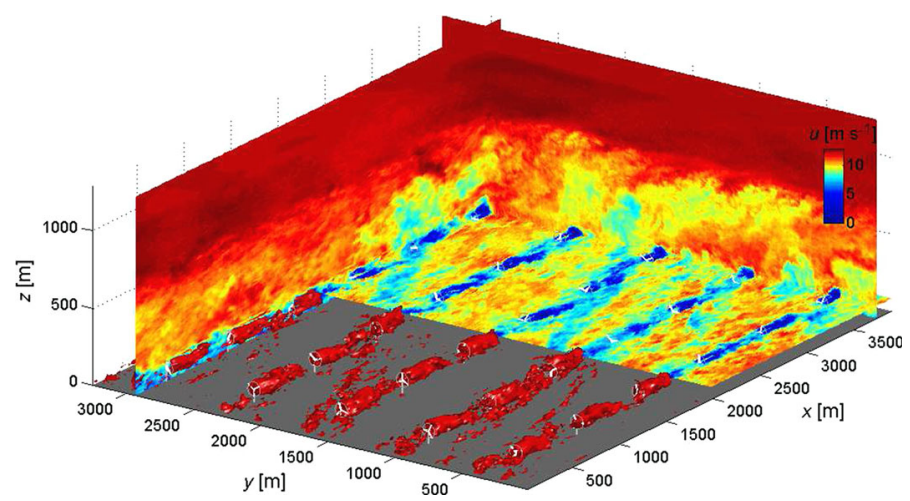

Fig. 2 Flow field in a fully developed wind-turbine array, a7 $\times 7$ case, shown by streamwise velocity contours (plotted on three representative $(x, z)-,(y, z)$-, and $(x, y)$-planes) and iso-surface of vorticity

case. Results clearly reveal the extraction of kinetic energy by the turbines. The presence of the wind farm increases the boundary-layer height by approximately $150 \mathrm{~m}$ (about $16 \%$ ) after $10 \mathrm{~h}$. It also leads to an increase of about $0.5 \mathrm{~K}$ in land-surface temperature, and a slight reduction of about $0.03 \mathrm{~K}$ in the vertically-integrated CBL temperature, which is consistent with the reduction in the surface heat flux (shown later). Table 2 presents the final (at $10 \mathrm{~h}$ ) changes of land-surface and vertically-integrated temperatures induced by the wind farm for all the layouts considered here. The table shows that denser wind-farm layouts bear larger differences with respect to the baseline (no-farm) case. Moreover, for a given turbine density, the staggered wind farm bears larger differences than its aligned counterpart. The primary reason is that, compared to the aligned counterpart, the staggered wind-farm configuration yields greater energy extraction (shown later). This yields greater downward momentum transport and more efficient mixing, as shown in recent studies (e.g., Markfort et al. 2012).

Figure 5 compares vertical profiles of the total turbulent momentum flux (defined as $\left(\left\langle\widetilde{u}^{\prime} \widetilde{w}^{\prime}+\tau_{13}\right\rangle^{2}+\left\langle\widetilde{v}^{\prime} \widetilde{w}^{\prime}+\tau_{23}\right\rangle^{2}\right)^{\frac{1}{2}}$, where the resolved fluctuation of an arbitrary variable, $a$, is written as $\widetilde{a}^{\prime}=\widetilde{a}-\langle\widetilde{a}\rangle$ ) and the total turbulent kinematic heat flux (defined as $\left\langle\tilde{\theta}^{\prime} \widetilde{w}^{\prime}+q_{3}\right\rangle$ ) obtained from the a5 $\times 5$ wind-farm case and the baseline case. In the baseline case, the momentum flux shows a near-linear decrease in magnitude with height. It is evident that the presence of the wind farm dramatically changes the momentum and heat-flux profiles. From both profiles, it is also clear that the wind farm increases the boundary-layer height by about $16 \%$. The surface momentum flux (and thus the friction velocity) is reduced due to the extraction of momentum by the wind turbines. In line with results from previous studies (e.g., Calaf et al. 2011; Markfort et al. 2012), the maximum magnitude of the turbulent vertical momentum flux is found at the turbine top-tip height. At that level, the high shear found at the upper edge of the turbine wakes leads to high production of turbulence kinetic energy 


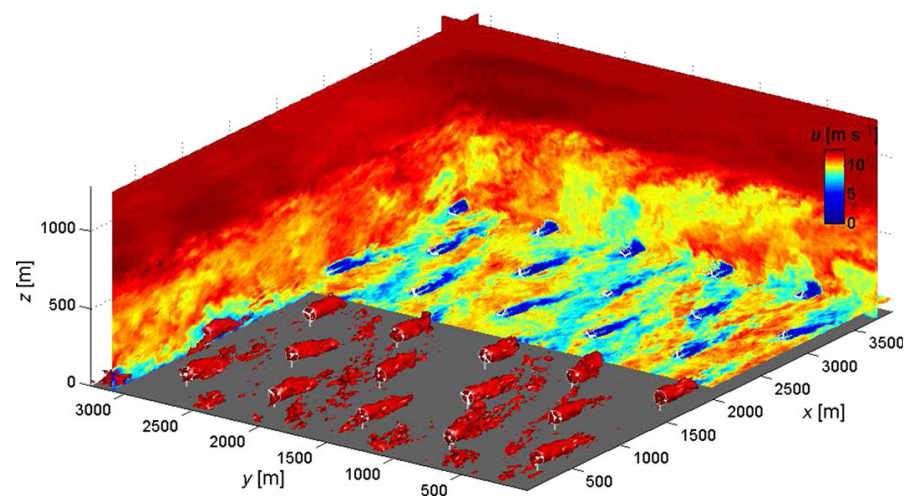

Fig. 3 Flow field in a fully developed wind-turbine array, s7 $\times 7$ case, shown by streamwise velocity contours (plotted on three representative $(x, z)-,(y, z)$-, and $(x, y)$-planes) and iso-surface of vorticity
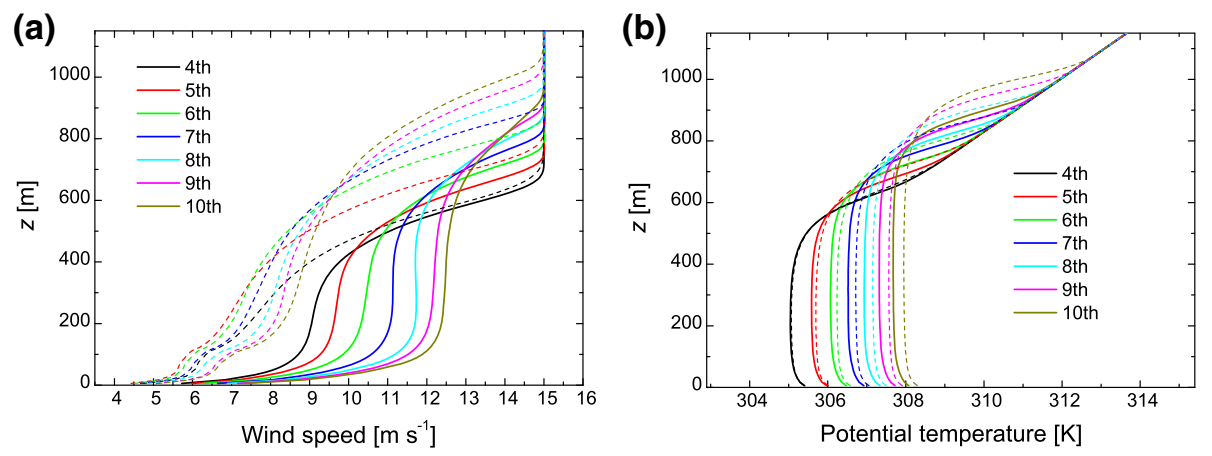

Fig. 4 Vertical profiles of $\mathbf{a}$ mean wind speed and $\mathbf{b}$ mean potential temperature, obtained from the baseline case (solid line) and the a $\times 5$ case (dashed line)

Table 2 Final $(10 \mathrm{~h}$ ) temperature difference between wind-farm and baseline (no-farm) cases

\begin{tabular}{lrrrrrr}
\hline Case & $\mathrm{s} 5 \times 5$ & $\mathrm{a} 5 \times 5$ & $\mathrm{~s} 6 \times 6$ & $\mathrm{a} 6 \times 6$ & $\mathrm{~s} 7 \times 7$ & $\mathrm{a} 7 \times 7$ \\
\hline$\Delta \theta_{\mathrm{S}}(\mathrm{K})$ & 0.650 & 0.623 & 0.524 & 0.512 & 0.429 & 0.414 \\
$\Delta \theta_{\mathrm{BL}}(\mathrm{K})$ & -0.0365 & -0.0336 & -0.0289 & -0.0269 & -0.0236 & -0.0215
\end{tabular}

$\Delta \theta_{\mathrm{S}}:$ temperature change on the land surface; $\Delta \theta_{\mathrm{BL}}:$ temperature change over the boundary layer (verticallyintegrated mean over $0-1200 \mathrm{~m}$ )

(TKE, $e=\left(\sigma_{u}^{2}+\sigma_{v}^{2}+\sigma_{w}^{2}\right) / 2$, where $\sigma_{u}^{2}, \sigma_{v}^{2}$ and $\sigma_{w}^{2}$ are the variances of the three velocity components) and, in turn, large TKE and momentum flux.

The warming produced by wind farms under stable conditions is caused by the enhanced vertical entrainment of relatively warmer air from higher altitudes (Baidya Roy and Traiteur 2010; Lu and Porté-Agel 2011; Zhou et al. 2012). Under convective conditions, current results show that the land-surface temperature and the near-surface temperature are increased, but the vertically-integrated temperature is slightly reduced. In comparison with the ABL flows under stable conditions, the mixing under convective conditions is already very large even without turbines; hence, the turbine-enhanced turbulent mixing plays a relatively smaller role in the temperature distribution. 

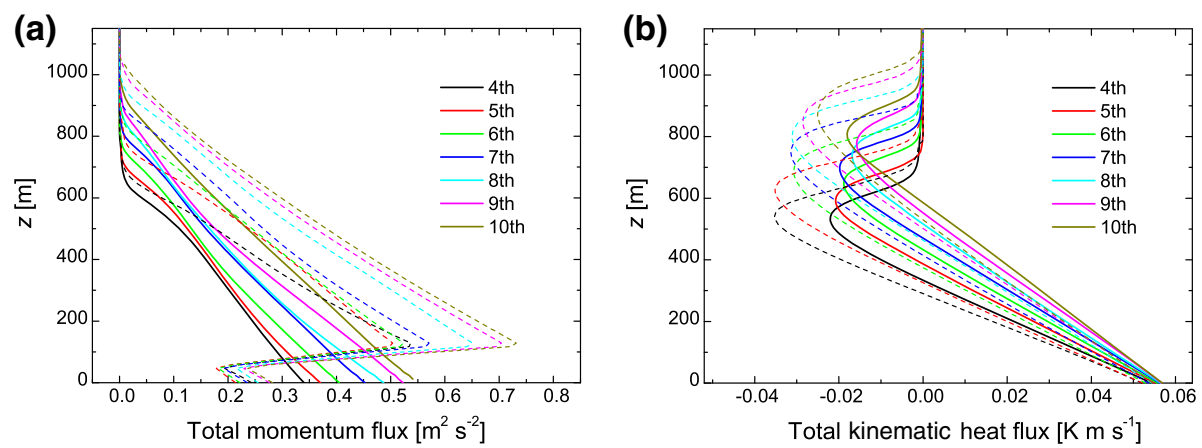

Fig. 5 Vertical profiles of a total momentum flux and $\mathbf{b}$ total kinematic heat flux, obtained from the baseline case (soild line) and the a5 $\times 5$ case (dashed line)

The vertical profile of the turbulent heat flux, shown in Fig. 5b, provides a better understanding of the thermal exchanges and consequent temperature changes induced by the wind farms. In the current scenario, wind-turbine blade motions lead to relatively smaller changes in the turbulent heat flux near the surface, compared with the reduction in heat flux magnitude previously reported under stable conditions (see Fig. 19b in Lu and Porté-Agel 2011). However, near the boundary-layer top, the turbulent heat-flux profiles reveal a largely enhanced entrainment flux in the presence of wind turbines. Specifically, the entrainment-flux to surface-flux ratio increases from 0.29 to 0.48 due to the wind-farm effect. The enhanced entrainment at the top of the boundary layer due to the presence of wind farms indicates increased downward flux of relatively warmer air in the entrainment layer. As a result, even though the near-surface temperature is slightly higher, the temperature in the entrainment layer is considerably lower than that in the baseline case. This is consistent with the fact that the wind turbines act as large roughness elements producing a substantial enhancement of momentum flux and TKE at the wind-turbine top-tip level and throughout the boundary layer. Moreover, the momentum transfer to the wind-turbine region in very large wind farms is achieved mainly by entraining warmer air from the free atmosphere. Also, an increased shear at the entrainment layer is expected to lead to a larger fraction of entrainment flux (relative to the surface flux) as shown in previous studies of the CBL (e.g., Pino et al. 2003; Conzemius and Fedorovich 2006). This entrainment warming effect is compensated by the reduced surface heat flux. This is in contrast to the stable boundary-layer case, for which both entrainment and surface fluxes contribute to the warming of the boundary layer.

Regarding the overall thermal energy budget, the 4-7\% reduction in surface heat flux induced by the wind farm is consistent with the decrease in the vertically-integrated temperature. It also leads to larger heat flux into the soil (shown later). For the same turbine density, the differences between the surface fluxes for the staggered and aligned layouts are not significant. In contrast, the effect of wind-turbine density on the surface fluxes is evident. In particular, denser wind-farm layouts bear lower surface heat flux, which yields larger temperature differences as shown in Table 2.

The Richardson number is an important dimensionless stability parameter. In Fig. 6, we investigate stability changes by presenting the vertical profiles of the flux Richardson number,

$$
R i_{f}=\frac{\frac{g}{\Theta_{0}}\left\langle\tilde{\theta}^{\prime} \widetilde{w}^{\prime}+q_{3}\right\rangle}{\left\langle\widetilde{u}^{\prime} \widetilde{w}^{\prime}+\tau_{13}\right\rangle \frac{\partial\langle\widetilde{u}\rangle}{\partial z}+\left\langle\widetilde{v}^{\prime} \widetilde{w}^{\prime}+\tau_{23}\right\rangle \frac{\partial\langle\widetilde{v}\rangle}{\partial z}},
$$


Fig. 6 Vertical profiles of the flux Richardson number obtained from the baseline case and wind farm cases

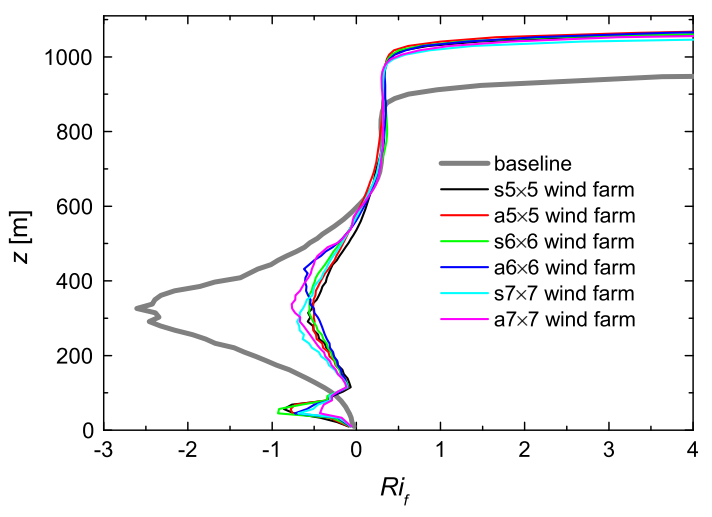

where results show that all wind-farm cases yield similar profiles of $R i_{f}$. Below the windturbine level, the flow is more unstable compared with the baseline case. This can be explained by the fact that the reduction in the magnitude of the momentum flux, due to the slowdown of the flow induced by the wind-turbine blade motions in that region, is relatively greater compared with the reduction in the heat flux. In the wind-turbine wake region and above, the flow is, in contrast, less unstable. The change of stability of the flow is associated with the turbulence enhancement produced by the wake flows. The wind-farm wake induces a higher momentum flux and a higher mean shear around the top-tip level, compared with the no-farm baseline case. This, together with the reduction in the turbulent heat flux, makes the magnitude of the Richardson number (and the relative effect of stability) smaller.

\section{Spatial Distributions}

Figure 7 presents spatial distributions of the time-averaged (over the last hour) surface heat flux obtained from the a $\times 5$ case and the $s 5 \times 5$ case. Even though both layouts yield similar mean values of the surface heat flux, it is clear that the staggered case yields a more uniform distribution. Specifically, the difference between the maximum and minimum surface heat flux is about $0.8 \%$ in the staggered wind farm and $2.0 \%$ in the aligned wind farm. In line with experimental measurements (Zhang et al. 2013a), both layouts show the surface-heat-flux distribution is heterogeneous. The maximum surface heat flux appears in the region immediately behind the wind turbine. It should be noted that the aligned wind farm yields a distinct trend on either side of the column of turbines, with larger heat flux on the left-hand side of the wind turbine (looking from the front) and lower heat flux on the right-hand side of the wind turbine. This is mainly caused by the turbine-induced flow rotation and the multiple-wake interaction. Flow on the left is on average moving downward, as also shown previously in Lu and Porté-Agel (2011) and Porté-Agel et al. (2011), thus transporting high-speed $\left(\widetilde{u}^{\prime}>0\right)$ momentum down from higher levels and enhancing mixing (Fig. 8a). As a consequence, there exists a difference of $0.3 \mathrm{~K}$ between the maximum and minimum temperatures on the land, as shown in Fig. 8b. Field studies (e.g., Rajewski et al. 2013) have also shown that the presence of wind turbines can induce heterogeneous spatial distributions of heat flux and temperature.

Figures 9 and 10 present the filled contours of the time-averaged streamwise velocity component in a vertical plane and a horizontal plane passing through the turbine axes, obtained 
(a)

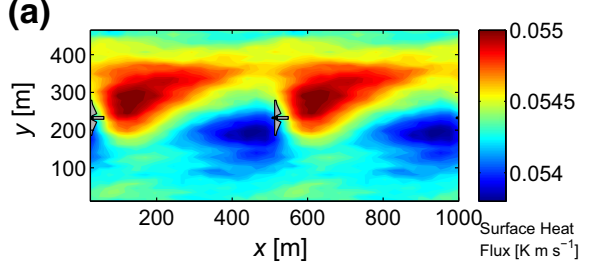

(b)

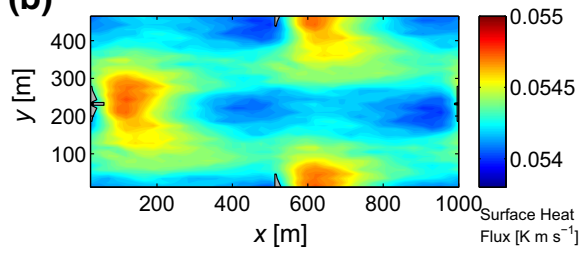

Fig. 7 Time-averaged surface heat flux from a the a5 $\times 5$ case and $\mathbf{b}$ the $s 5 \times 5$ case

(a)

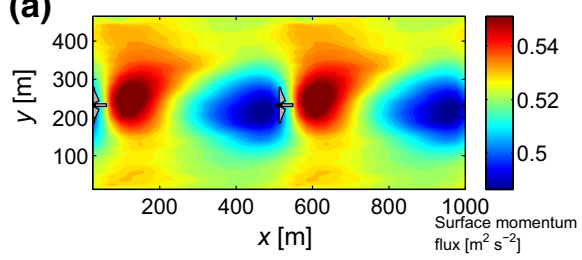

(b)

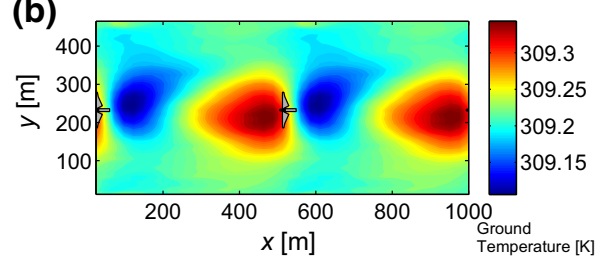

Fig. 8 Time-averaged a surface momentum flux and $\mathbf{b}$ ground temperature from the a5 $\times 5$ case

(a)

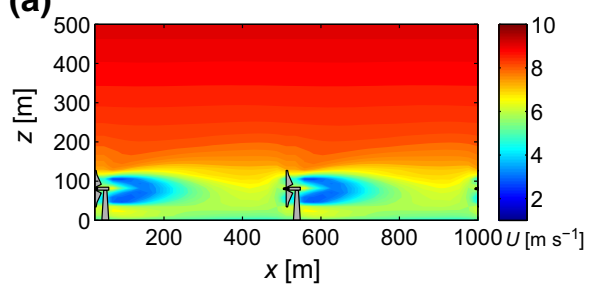

(b)

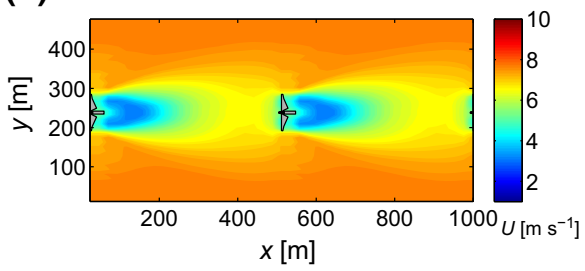

Fig. 9 Time-averaged streamwise velocity obtained from the a5 $\times 5$ case: $\mathbf{a}$ in the vertical plane through the wind-turbine axis; $\mathbf{b}$ in the horizontal plane at the wind-turbine hub height

(a)

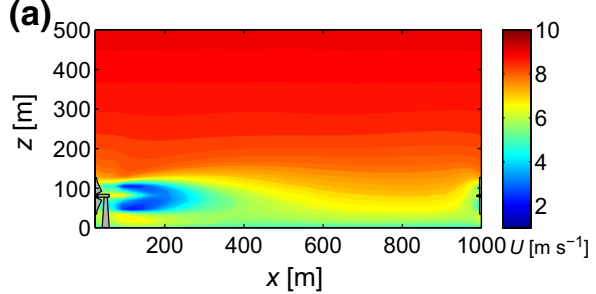

(b)

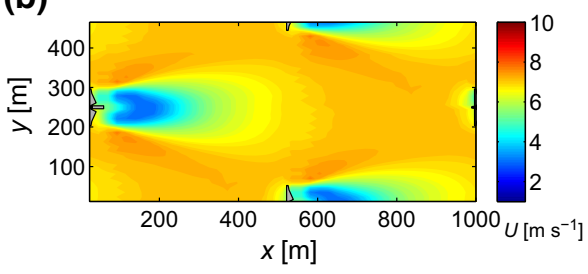

Fig. 10 Time-averaged streamwise velocity component obtained from the $s 5 \times 5$ case: $\mathbf{a}$ in the vertical plane through the wind-turbine axis; $\mathbf{b}$ in the horizontal plane at the wind-turbine hub height

from the a5 $\times 5$ case and the s $5 \times 5$ case, respectively. Comparing the two horizontal crosssection contours, it is clear that the staggered farm yields a more uniform flow. Also, in the staggered farm, the turbine wakes have a longer distance to recover, which results in a slightly higher wind speed in front of the next downstream turbine and, consequently, a larger power output compared with the aligned counterpart (shown later).

The combined effect of velocity deficit/shear and increased turbulence causes increased fatigue loads on wind turbines (e.g., Crespo et al. 1999; Thomsen and Sørensen 1999; Vermeer et al. 2003; Eggers et al. 2003). Figures 11 and 12 show the filled contours of the TKE in 

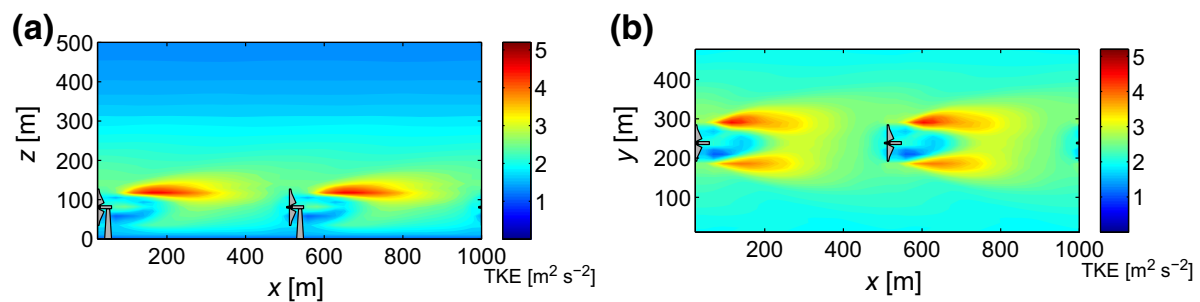

Fig. 11 Turbulence kinetic energy obtained from the a5 $\times 5$ case: $\mathbf{a}$ in the vertical plane through the windturbine axis; $\mathbf{b}$ in the horizontal plane at the wind-turbine hub height
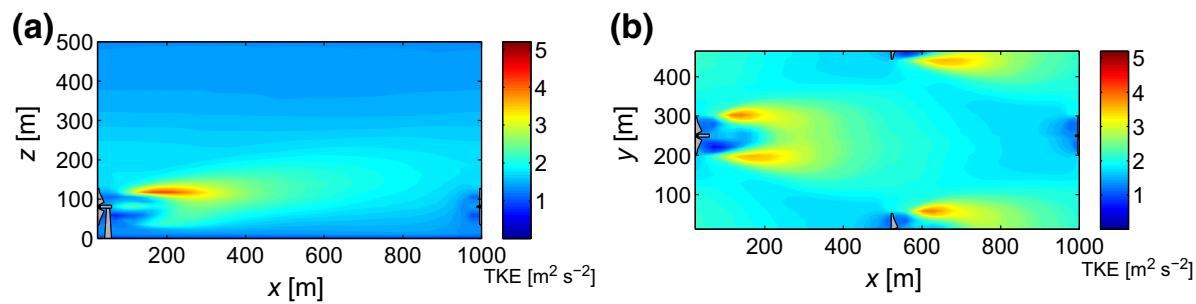

Fig. 12 Turbulence kinetic energy obtained from the $55 \times 5$ case: $\mathbf{a}$ in the vertical plane through the windturbine axis; $\mathbf{b}$ in the horizontal plane at the wind-turbine hub height

a vertical plane and a horizontal plane passing through the turbine axes, obtained from the a5 $\times 5$ case and the $55 \times 5$ case, respectively. In agreement with previous studies of windturbine wakes in boundary-layer flows (e.g., Wu and Porté-Agel 2011; Yang et al. 2014; Xie and Archer 2014), the turbulence intensity above the hub-height is found to be larger than that below the hub-height. The primary cause is the larger velocity shear (and associated production of TKE) observed near the turbine top level. The maximum turbulence intensity is found at that level and at a distance of approximately $1 D-3 D$, instead of $3 D-5 D$ observed in stand-alone wind-turbine wakes (Wu and Porté-Agel 2011; Porté-Agel et al. 2011; Zhang et al. 2013b; Xie and Archer 2014) and wind-farm wakes in a stable boundary layer (Lu and Porté-Agel 2011). The faster recovery of the wind-turbine wakes in the CBL compared to other situations is also observed in numerical and experimental studies (e.g., Zhang et al. 2013b; Abkar and Porté-Agel 2015), and it is attributed to the increased turbulent mixing induced by convection. Results also show that the magnitude of the maximum TKE is larger in the aligned layout case $\left(4.6 \mathrm{~m}^{2} \mathrm{~s}^{-2}\right)$, compared with the staggered one $\left(3.9 \mathrm{~m}^{2} \mathrm{~s}^{-2}\right)$. Like with the velocity deficit, the relatively longer streamwise distance between turbines in the staggered case allows the turbulence levels to decay to lower values before encountering the next downwind turbine. It implies that the staggered layout would yield less fatigue loads on wind turbines. It is interesting to note that the maximum added TKE (local TKE maximum behind the turbine minus TKE level upstream of the turbine) has a similar magnitude (about $2 \mathrm{~m}^{2} \mathrm{~s}^{-2}$ ) for both layouts. It is also similar to the values found in previous simulations of stand-alone turbine wakes (Abkar and Porté-Agel 2015) as well as wind farms in a relatively deep neutral boundary layer (Porté-Agel et al. 2013). It is however much larger than that reported by Lu and Porté-Agel (2011) for a wind farm in a relatively shallow stable boundary layer, where the maximum TKE in the wakes was found to be about $0.6 \mathrm{~m}^{2} \mathrm{~s}^{-2}$. 

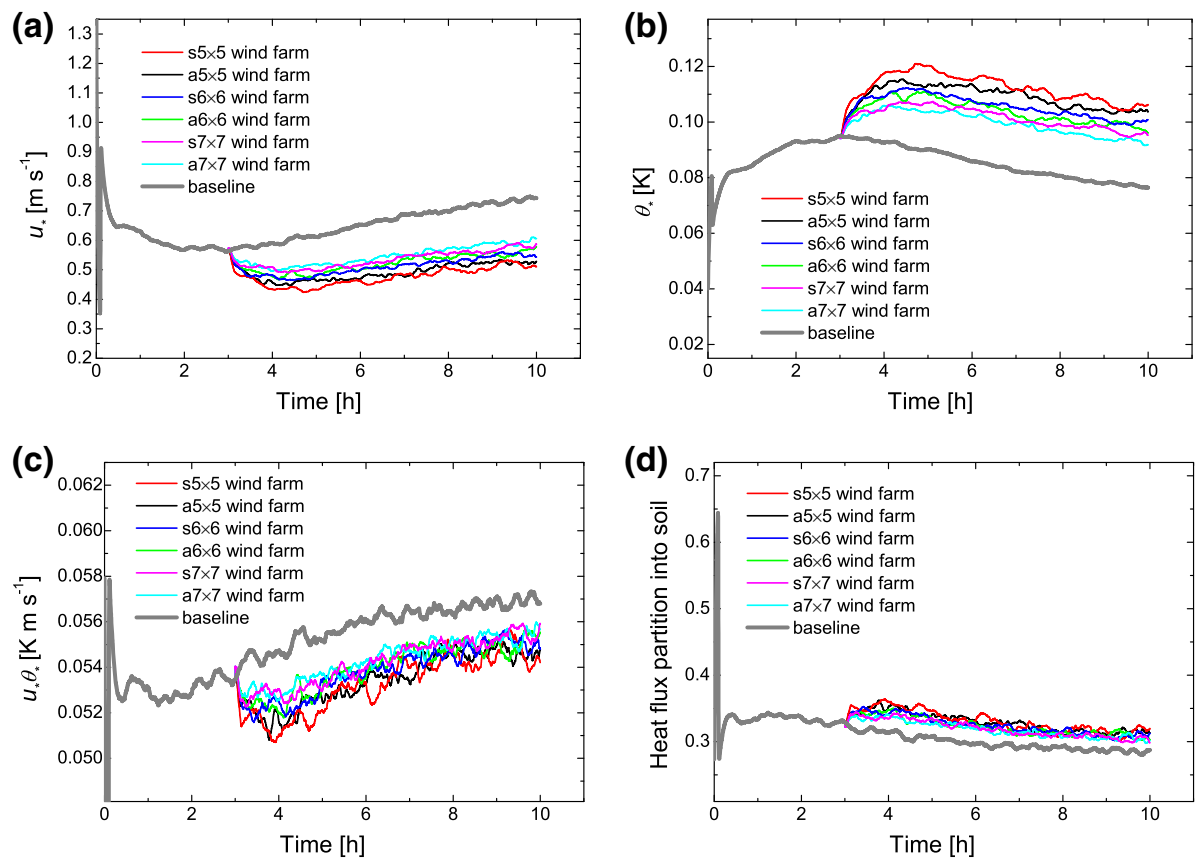

Fig. 13 Evolutions of a friction velocity, $\mathbf{b}$ temperature scale, $\mathbf{c}$ surface heat flux, and $\mathbf{d}$ heat flux partition into soil

\section{Temporal Measures}

Figure 13 shows the temporal evolution of the averaged friction velocity, temperature scale, surface heat flux and heat-flux partition into the soil. The averaging is taken over the horizontal surface plane. Undoubtedly, wind turbines reduce the wind speed, which in turn yields a decrease in the friction velocity. Despite the increase in $\theta_{*}$ induced by the wind farms, the net effect is a reduction of 4-7\% in the surface heat flux. The reduction is slightly greater with increasing wind-turbine density. As a result of the reduction in the surface heat flux, more energy is available to heat the soil, causing higher land-surface temperatures as shown in Table 2.

Figure 14 shows the temporal evolution of the boundary-layer height, the averaged convective velocity scale $\left(w_{*}=\left(\frac{g}{\Theta_{0}} u_{*} \theta_{*} z_{i}\right)^{\frac{1}{3}}\right)$, large-eddy turnover time $\left(z_{i} / w_{*}\right)$ and stability parameter $\left(-z_{i} / L\right)$. The effects of wind-turbine spacing and layout on the first three variables are not significant. All cases show approximately $16 \%$ growth of the boundary layer, and $10 \%$ increase in updraft speed and turn-over time. The increased value of the stability parameter indicates that the wind-farm wake significantly changes the static stability of the flow, as shown above in Fig. 6. Not only the boundary-layer height is increased, but also the magnitude of the Obukhov length is significantly reduced. This is because the Obukhov length is computed using surface fluxes, and the reduction in the magnitude of the surface momentum flux is relatively greater compared with the reduction in the surface heat flux.

For each wind turbine, its power production can be related to the incoming wind speed measured at hub height (Bozkurt et al. 2014). Here, we adopt the SWT-2.3-93 power curve 

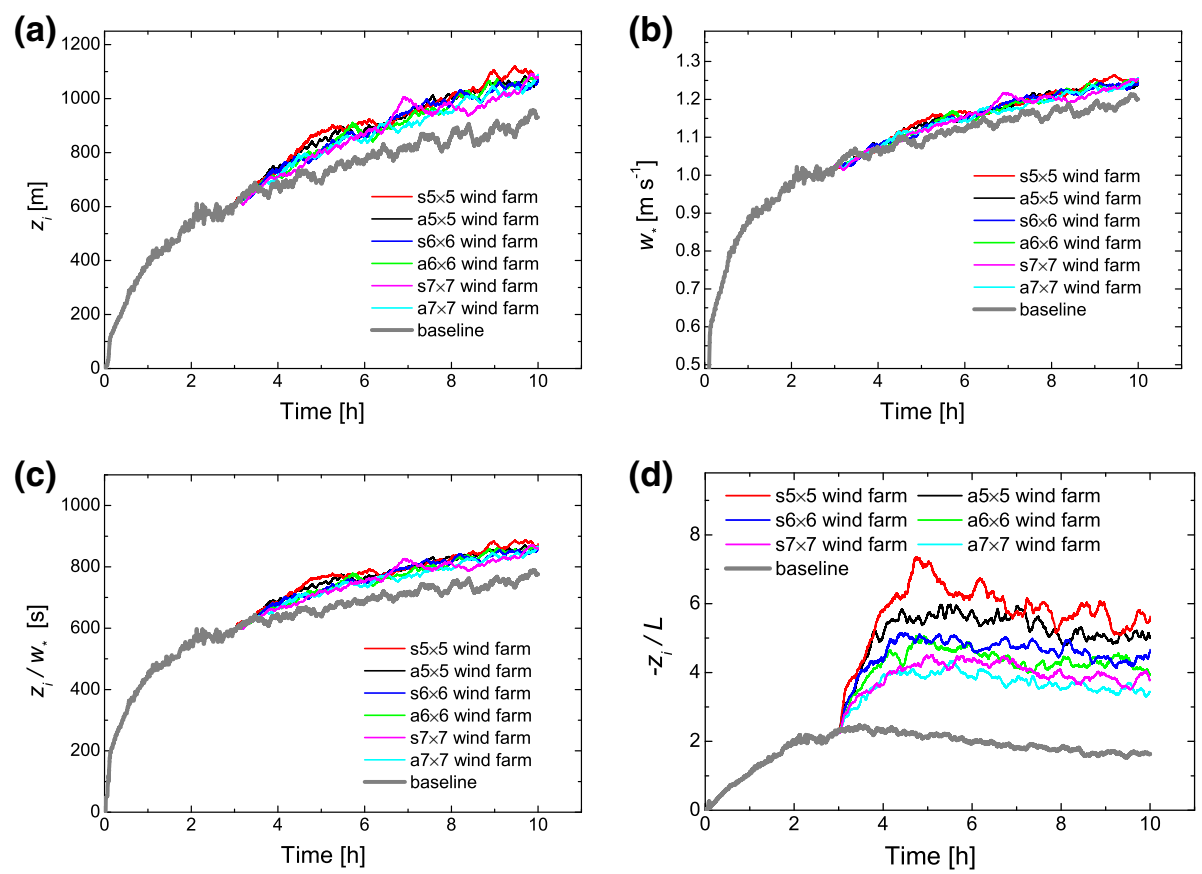

Fig. 14 Evolutions of a boundary-layer height, $\mathbf{b}$ convective velocity scale, $\mathbf{c}$ large-eddy turnover time, and d stability parameter

Fig. 15 Averaged wind-turbine power output

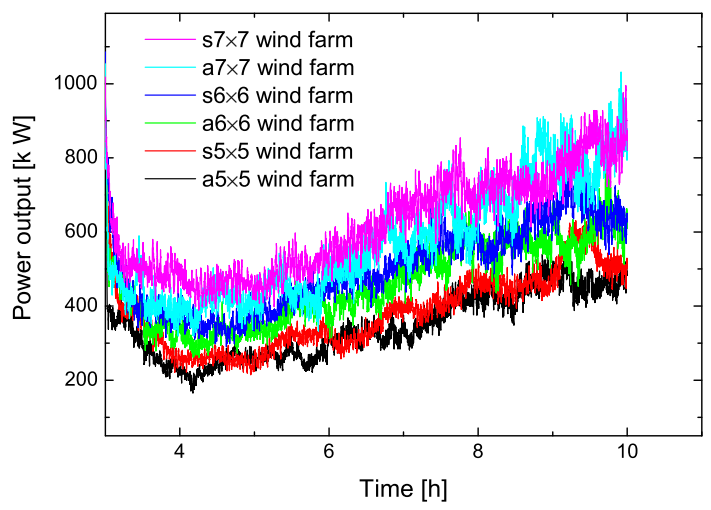

from the manufacturer to compute the wind-turbine power output using the wind speed $1 D$ upwind of the turbine. Figure 15 shows the temporal evolution of the wind-power production, which is averaged over all the wind turbines. We summarize the mean normalized windturbine power output in Table 3. It is clear that, as expected, the lower the turbine density, the higher the power extracted by each individual turbine. Moreover, for the same turbine density, results show that the staggered wind farms yield about $10 \%$ more power output than their aligned counterparts. A similar increase has also been reported by Abkar and Porté-Agel (2013) in simulations of a conventionally neutral ABL. 
Table 3 Mean normalized (using the mean wind-turbine power output from the $a 5 \times 5$ wind farm) windturbine power output

\begin{tabular}{lllllll}
\hline Case & $\mathrm{a} 5 \times 5$ & $\mathrm{~s} 5 \times 5$ & $\mathrm{a} 6 \times 6$ & $\mathrm{~s} 6 \times 6$ & $\mathrm{a} 7 \times 7$ & $\mathrm{~s} 7 \times 7$ \\
\hline Normalized power $(\%)$ & 100 & 111 & 131 & 143 & 163 & 176 \\
\hline
\end{tabular}

\section{Conclusions}

In this study, large-eddy simulations have been used, for the first time, to investigate the effects of very large wind farms on a CBL. The simulation results show that the wind-turbine wakes enhance the vertical mixing, resulting in changes to the ABL flow stability. Results also reveal that wind farms lead to a slight reduction in the surface heat flux, an increase in land-surface temperature, and a slight reduction in the vertically-integrated temperature. These effects increase with increasing wind-turbine density. It should be noted here that the warming effect on the land surface is due to the redistribution of energy available for the soil and the air; in particular, a reduction in the sensible heat flux is associated with an increase in the heat flux into the soil. Results also show that the spatial distribution of the surface heat flux is heterogeneous. In addition, the connection between the surface heat-flux heterogeneity and the coherent wake column rotation in aligned wind farms suggests that it is essential to simulate the wake rotation effects in numerical models of turbine-wake flows in order to reproduce the spatial distribution of the surface heat flux.

The staggered wind-farm layout is characterized by a relatively longer separation between consecutive downwind turbines compared to the aligned counterpart. As a result, the staggered layout allows the wakes to recover more, exposing the downwind turbines to higher local wind speeds (leading to higher wind-power production) and lower turbulence intensity levels (leading to lower fatigue loads).

This study provides evidence and quantification of the impact of wind farms on daytime convective boundary layers. This information is of great importance for optimizing the design of wind farms and also for developing improved parametrisation of turbulent fluxes in weather and climate models. Future work will focus on further investigation of windfarm-atmosphere interactions under more realistic conditions, including complex terrain (e.g. topography and/or surface heterogeneity), non-stationary flow conditions, and finitesize wind farms.

Acknowledgments This research was supported by the Swiss National Science Foundation (Grant 200021132122 and IZERZ0-142168), and the Swiss Innovation and Technology Committee (CTI) within the context of the Swiss Competence Center for Energy Research 'FURIES: Future Swiss Electrical Infrastructure.' Computing resources were provided by the Swiss National Supercomputing Centre (CSCS) under project s542. The authors are indebted to Dr. Wei Zhang and Dr. Corey D. Markfort for useful discussions.

\section{References}

Abkar M, Porté-Agel F (2013) The effect of free-atmosphere stratification on boundary-layer flow and power output from very large wind farms. Energies 6:2338-2361

Abkar M, Porté-Agel F (2015) Influence of atmospheric stability on wind-turbine wakes: a large-eddy simulation study. Phys Fluids 27:035104

Agee E, Gluhovsky A (1999) LES model sensitivities to domains, and large-eddy timescales. J Atmos Sci 56:599-604 
Arya SP (2001) Introduction to micrometeorology, 2nd edn. Academic Press, London, 420 pp

Baidya Roy S (2011) Simulating impacts of wind farms on local hydrometeorology. J Wind Eng Ind Aerodyn 99:491-498

Baidya Roy S, Pacala SW, Walko RL (2004) Can large wind farms affect local meteorology? J Geophys Res 109:1-6

Baidya Roy S, Traiteur JJ (2010) Impacts of wind farms on surface air temperatures. PNAS 107(42):17899_ 17904

Beare RJ, MacVean MK, Holtslag AAM, Cuxart J, Esau I, Golaz J-C, Jimenez MA, Khairoutdinov M, Kosovic B, Lewellen D, Lund TS, Lundquist JK, McCabe A, Moene AF, Noh Y, Raasch S, Sullivan P (2006) An intercomparison of large-eddy simulations of the stable boundary layer. Boundary-Layer Meteorol 118(2):247-272

Bozkurt TG, Giebel G, Poulsen NK, Mirzaei M (2014) Wind speed estimation and parametrization of wake models for downregulated offshore wind farms within the scope of PossPOW project. J Phys 524(012156):1-7

Businger JA, Wynagaard JC, Izumi Y, Bradley EF (1971) Flux-profile relationships in the atmospheric surface layer. J Atmos Sci 28:181-189

Calaf M, Parlange MB, Meneveau C (2011) Large eddy simulation study of scalar transport in fully developed wind-turbine array boundary layers. Phys Fluids 23:126603

Canuto C, Hussaini MY, Quarteroni A, Zang TA (1988) Spectral methods in fluid dynamics. Springer, Berlin, $567 \mathrm{pp}$

Conzemius RJ, Fedorovich E (2006) Dynamics of sheared convective boundary layer entrainment. Part I: Methodological background and large-eddy simulations. J Atmos Sci 63:1151-1178

Conzemius RJ, Fedorovich E (2008) A case study of convective boundary layer development during IHOP 2002: numerical simulations compared to observations. Mon Weather Rev 136:2305-2320

Crespo A, Hernández J, Frandsen S (1999) Survey of modelling methods for wind turbine wakes and wind farms. Wind Energy 2:1-24

Deardorff JW (1974) Three-dimensional numerical study of the height and mean structure of a heated planetary boundary layer. Boundary-Layer Meteorol 7:81-106

Eggers AJ, Digumarthi R, Chaney K (2003) Wind shear and turbulence effects on rotor fatigue and loads control. J Sol Energy Eng 125(4):402-409

Fitch A, Lundquist JK, Olson JB (2013) Mesoscale influences of wind farms throughout a diurnal cycle. Mon Weather Rev 141:2173-2198

Fitch A, Olson JB, Lundquist JK, Dudhia J, Gupta AK, Michalakes J, Barstad I (2012) Local and mesoscale impacts of wind farms as parameterized in a mesoscale NWP model. Mon Weather Rev 140:3017-3038

Holton JR (2004) An introduction to dynamic meteorology, 4th edn. Elsevier Academic Press, Boston, 535 $\mathrm{pp}$

Kosovic B, Curry JA (2000) A large eddy simulation study of a quasi-steady, stably stratified atmospheric boundary layer. J Atmos Sci 57:1052-1068

Laursen J, Enevoldsend P, Hjort S (2007) 3D CFD quantification of the performance of a multi-megawatt wind turbine. J Phys 75(012007):1-13

Leloudas G (2006) Optimization of wind turbines with respect to noise. Master's thesis, Department of Mechanical Engineering, Technical University of Denmark

Lu H, Porté-Agel F (2010) A modulated gradient model for large-eddy simulation: application to a neutral atmospheric boundary layer. Phys Fluids 22:015109

Lu H, Porté-Agel F (2011) Large-eddy simulation of a very large wind farm in a stable atmospheric boundary layer. Phys Fluids 23:065101

Lu H, Porté-Agel F (2013) A modulated gradient model for scalar transport in large-eddy simulation of the atmospheric boundary layer. Phys Fluids 25:015110

Lu H, Porté-Agel F (2014) On the development of a dynamic non-linear closure for large-eddy simulation of the atmospheric boundary layer. Boundary-Layer Meteorol 151(3):429-451

Markfort CD, Zhang W, Porté-Agel F (2012) Turbulent flow and scalar transport through and over aligned and staggered wind farms. J Turbul 13(33):1-36

Mason PJ (1989) Large-eddy simulation of the convective atmospheric boundary layer. J Atmos Sci 46(11):1492-1516

Moeng C-H (1984) A large-eddy-simulation model for the study of planetary boundary-layer turbulence. J Atmos Sci 41:2052-2062

Moeng CH, Sullivan PE (1994) A comparison of shear- and buoyancy-driven planetary boundary layer flows. J Atmos Sci 51(7):999-1022

Pino D, Arellano JV-GD, Duynkerke PG (2003) The contribution of shear to the evolution of a convective boundary layer. J Atmos Sci 60:1913-1926 
Porté-Agel F, Wu Y-T, Chen C-H (2013) A numerical study of the effects of wind direction on turbine wakes and power losses in a large wind farm. Energies 6:5297-5313

Porté-Agel F, Wu Y-T, Lu H, Conzemius R (2011) Large-eddy simulation of atmospheric boundary layer flow through wind turbines and wind farms. J Wind Eng Ind Aerodyn 99(4):154-168

Rajewski DA, Takle ES, Lundquist JK, Oncley S, Prueger JH, Horst TW, Rhodes ME, Pfeiffer R, Hatfield JL, Spoth KK, Doorenbos RK (2013) Crop wind energy experiment (CWEX): observations of surface-layer, boundary layer, and mesoscale interactions with a wind farm. Bull Am Meteorol Soc 94:655-672

Roode SRD, Duynkerke PG (2004) Large-eddy simulation: How large is large enough? J Atmos Sci 61:403421

Sorbjan Z (2006) Statistics of scalar fields in the atmospheric boundary layer based on large-eddy simulations. Part II: Forced convection. Boundary-Layer Meteorol 119:57-79

Stull RB (1988) An introduction to boundary-layer meteorology. Kluwer Academic Publishers, Dordrecht, $666 \mathrm{pp}$

Thomsen K, Sørensen P (1999) Fatigue loads for wind turbines operating in wakes. J Wind Eng Ind Aerodyn 80:121-136

Vermeer LJ, Sørensen JN, Crespo A (2003) Wind turbine wake aerodynamics. Prog Aerosp Sci 39:467-510

Wu Y-T, Porté-Agel F (2011) Large-eddy simulation of wind-turbine wakes: evaluation of turbine parameterizations. Boundary-Layer Meteorol 138(3):345-366

Xie S, Archer C (2014) Self-similarity and turbulence characteristics of wind turbine wakes via large-eddy simulation. Wind Energy: 457-475

Yang D, Meneveau C, Shen L (2014) Effect of downwind swells on offshore wind energy harvesting-a large-eddy simulation study. Renew Energy 70:11-23

Zhang W, Markfort CD, Porté-Agel F (2013a) Experimental study of the impact of large-scale wind farms on land-atmosphere exchanges. Environ Res Lett 8:015002

Zhang W, Markfort CD, Porté-Agel F (2013b) Wind-turbine wakes in a convective boundary layer: a windtunnel study. Boundary-Layer Meteorol 146:161-179

Zhou L, Tian Y, Baidya Roy S, Thorncroft C, Bosart LF (2012) Impacts ofwind farms on land surface temperature. Nat Clim Change 2:539-543 